\title{
Effects of heat stress on the expression of the coxsackievirus and adenovirus receptor in mouse skin keratinocytes
}

\author{
XIANGDONG DENG ${ }^{1}$, CHIYU JIA ${ }^{2}$, FUXING CHEN $^{3}$, JUNQUAN LIU ${ }^{3}$ and ZONGHAI ZHOU ${ }^{3}$ \\ ${ }^{1}$ The Graduate School, Chinese People's Liberation Army Medical College, Beijing 100039; \\ ${ }^{2}$ Plastic Beauty and Burn Repair Center, The 309th Hospital of the Chinese PLA, Beijing 100091; \\ ${ }^{3}$ The 97 th Hospital of the Chinese PLA, Xuzhou, Jiangsu 221004, P.R. China
}

Received April 4, 2013; Accepted July 15, 2013

DOI: $10.3892 /$ etm.2013.1230

\begin{abstract}
The aim of this study was to investigate the effects of heat stress on the expression of the coxsackievirus and adenovirus receptor (CAR) in mouse skin keratinocytes. Twenty BALB/c mice were randomly divided into two groups: the sham heat (control) and scald groups. Skin specimens were obtained $6 \mathrm{~h}$ after the treatments. Changes in the expression of CAR in skin keratinocyte samples were detected by immunohistochemistry, quantitative polymerase chain reaction and western blotting. In an in vitro assay, mouse skin keratinocytes were cultured and randomly divided into two groups: the normal control and heat stress groups. Six hours subsequently, the changes in CAR expression in the two groups were estimated by flow cytometry to determine the differences between the two groups. Heat stress significantly increased the expression of CAR in the mouse skin keratinocytes $(\mathrm{P}<0.05)$. The upregulation of CAR in mouse keratinocytes in burn wounds may be beneficial for restoring healing in organisms.
\end{abstract}

\section{Introduction}

Wound problems commonly occur in clinical practice; $\sim 1 \%$ of the global population suffers from persistent wound problems, and $5 \%$ of total medical costs are spent on wound treatments $(1,2)$. Accurate wound treatment is required to solve this problem effectively, and such treatment relies on a better understanding of the wound healing mechanism. However, wound healing is a complex biological process. Different types of wounds have different healing processes and the mechanisms have not yet been fully elucidated. The exchange of signals among cells, transmembrane conductance and intracellular signal transduction are the potential

Correspondence to: Professor Chiyu Jia, Plastic Beauty and Burn Repair Center, 309th Hospital of the Chinese PLA, No.17 Heishanhu, Beijing 100091, P.R. China

E-mail: chiyujiacn@yeah.net

Key words: heat stress, keratinocytes, coxsackie-adenovirus receptor, burn wound physical mechanisms controlling the process. As a result, signal transduction mechanisms in wound healing have been the focus of the majority of studies. Witherden et al (3) observed an increased coxsackievirus and adenovirus receptor (CAR) expression near the keratinised cells in a mouse skin wound biopsy. It was demonstrated that CAR was involved in a cell-to-cell contact signalling pathway that resulted in an increase in the number of local cell growth factors and inflammatory mediators, thereby promoting wound healing. These results indicated that CAR functions as a signalling molecule in skin wound biopsies.

CAR is a $46 \mathrm{kDa}$ type I transmembrane glycoprotein belonging to the immunoglobulin superfamily (4). In mice, CAR is mainly distributed in the heart, liver, brain, kidneys and lungs, with the highest expression level observed in the liver (5-7). Numerous studies have shown that CAR significantly functions as an important adhesion protein and molecule in viral infection (8-11) and the tumour development process (12-16). The correlation between CAR and wound healing was first described by Witherden et al (3). However, only the changes in CAR expression in the keratinocytes of skin wound biopsies have been observed; no other similar observations have been described for burn wounds, a different form of wound from a skin wound biopsy. To determine whether CAR exhibited similar expression changes in burn wounds, in vitro mouse and cellular experiments were performed in the present study. Such experiments were also conducted to observe the effects of the changes in CAR expression in thermally stimulated mouse skin keratinocytes. In addition, the function of CAR in the burn wound healing process was elucidated.

\section{Materials and methods}

Establishment of animal models. Twenty BALB/c mice (age, 6-8 weeks; 10 males/10 females; weight, 20-25 g; Academy of Military Medical Sciences, Beijing, China) were randomly divided into two groups. The mice remained awake while their backs were shaved. Following this, the depilated areas of one group (the scald group) were treated with hot water gauzes heated at $100^{\circ} \mathrm{C}$ for 1 to $3 \mathrm{sec}$. The other group (the sham heat or control group) was treated with humidity gauzes heated at room temperature. Six hours later, all the mice were sacrificed, and specimens of back skin were obtained for the subsequent 
experiment. This study was performed in strict accordance with the recommendations in the Guide for the Care and Use of Laboratory Animals of the National Institutes of Health. The animal use protocol was reviewed and approved by the Institutional Animal Care and Use Committee of the 309th Hospital of the Chinese PLA (Beijing, China).

Keratinocyte culture and thermal stimulation model. The dorsal skin from BALB/c foetal mice (gestational age, 20 days) was washed with $\mathrm{D}$-Hanks solution and cut into strips $(0.3 \times 1 \mathrm{~cm})$. The skin was added to $1.25 \mathrm{U} / \mathrm{ml}$ dispase II solution (Roche, Basel Switzerland) and digested at $4^{\circ} \mathrm{C}$ for $24 \mathrm{~h}$. Following this, the epidermis and dermis were separated, and the epidermis was cut in pieces, added to $1.25 \mu / \mathrm{ml}$ dispase II solution at $37^{\circ} \mathrm{C}$ and digested for $30 \mathrm{~min}$. All of the tissue fragments were removed via a mesh filter, while the remaining cells were collected by centrifugation and cultured in Epilife medium (Invitrogen Life Technologies, Carlsbad, CA, USA). After 3 to 4 days, the fused cells were digested and passaged. The third generation of cells was used and divided into two groups for the subsequent experiments. The first group (the normal control group) was cultured at $37^{\circ} \mathrm{C}$ in $5 \% \mathrm{CO}_{2}$ for $1 \mathrm{~h}$; the other group (the heat stress group) was cultured at $42^{\circ} \mathrm{C}$ in $5 \% \mathrm{CO}_{2}$ for $1 \mathrm{~h}$. The two groups of cells were subsequently cultured under normal conditions for $6 \mathrm{~h}$ and then harvested.

Immunohistochemistry. Following the dewaxing and hydration of the paraffin sections of the back skin samples, the antigens were retrieved by citric acid heating for $10 \mathrm{~min}$. Endogenous catalases were blocked using freshly prepared $2 \% \mathrm{ddH}_{2} \mathrm{O}$ at room temperature for $20 \mathrm{~min}$, and non-specific binding sites were blocked by horse serum for $30 \mathrm{~min}$. All the sections were incubated with a rabbit anti-mouse CAR antibody (Santa Cruz Biotechnology, Inc., Santa Cruz, CA, USA) at $4^{\circ} \mathrm{C}$ overnight and incubated with a secondary antibody (Santa Cruz Biotechnology, Inc.) at $37^{\circ} \mathrm{C}$ for $30 \mathrm{~min}$. Avidin/Biotin Complex (ABC) reagents (Vector Laboratories, Burlingame, CA, USA) were added under the previous conditions. Diaminobenzidine (DAB) colour reactions were viewed under a microscope (5-10 min). The samples were dehydrated and sealed using graded ethanol, dimethylbenzene and resin. In the blank control group, the primary antibody was replaced with phosphate-buffered saline (PBS). Under the microscope, a granular appearance on the cell surface or a homogeneous brown reaction product was considered to be a positive result.

Quantitative polymerase chain reaction ( $q P C R$ ). Total RNA was extracted from fresh skin specimens using RNeasy Plus Mini kit (Qiagen, Hilden, Germany) according to the manufacturer's instructions. Total RNA $(4 \mu \mathrm{g})$ was subjected to reverse transcription using a transcriptor high fidelity cDNA synthesis kit (Roche). Following this, total RNA, random hexamer primer $(2.0 \mu \mathrm{l})$ and $\mathrm{ddH}_{2} \mathrm{O}$ were added to obtain a final volume of $11.4 \mu \mathrm{l}$. The samples subsequently reacted at $65^{\circ} \mathrm{C}$ for $10 \mathrm{~min}$ and were placed immediately in an ice bath. Following this, $4.0 \mu 15 \mathrm{X}$ efficient reverse transcription buffer, $0.5 \mu 1$ RNase inhibitor, $2.0 \mu 1$ deoxynucleic acid mix, $1.0 \mu \mathrm{l}$ dithiothreitol (DTT) and $1.1 \mu \mathrm{l}$ efficient reverse transcription enzyme were added to obtain a final volume of $20 \mu \mathrm{l}$. The following two reaction phases were conducted at $50^{\circ} \mathrm{C}$ for $30 \mathrm{~min}$ and $85^{\circ} \mathrm{C}$ for $10 \mathrm{~min}$. The primer sequences were designed based on a GenBank (National Centre for Biotechnology Information, Bethesda, MD, USA) query: for CAR, forward primer, 5'-TACGAGTAACGATGTCAAGT-3'; reverse primer 5'-CCTGAAGGCTTAACAAGAAC-3'; for glyceraldehyde 3-phosphate dehydrogenase (GAPDH), forward primer 5'-TGAGTATGTCGTGGAGTC-3'; reverse primer 5'-CAATCTTGAGTGAGTTGTCAT-3'. The standard curve was then prepared. To detect the amplification efficiency of CAR and GAPDH by qPCR using RealmasterMix (SYBR-Green; Tiangen Biotechnology Co., Ltd., Beijing, China), the reverse transcription product cDNA was diluted five times by a gradient $\left(5^{0}, 5^{1}, 5^{2}, 5^{3}\right.$ and $\left.5^{4}\right)$. The reaction system comprised $1 \mu \mathrm{l}$ cDNA, $9 \mu \mathrm{l}$ 5X PCR buffer, $0.4 \mu \mathrm{l}$

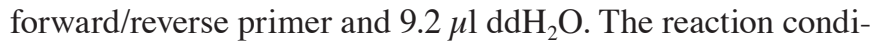
tions were as follows: one cycle of $95^{\circ} \mathrm{C}$ for $2 \mathrm{~min} ; 94^{\circ} \mathrm{C}$ for $15 \mathrm{sec}$ and $58^{\circ} \mathrm{C}$ for $10 \mathrm{sec}$; and 40 cycles of $68^{\circ} \mathrm{C}$ for $18 \mathrm{sec}$. The melting curve was analysed based on the following parameters: one cycle of $95^{\circ} \mathrm{C}$ for $1 \mathrm{~min}$; one cycle of $55^{\circ} \mathrm{C}$ for $1 \mathrm{~min}$; 57 cycles of $65-93^{\circ} \mathrm{C}$, read board for $0.06 \mathrm{sec}$ once a $0.5^{\circ} \mathrm{C}$ increase in temperature occurred, and read board for $0.05 \mathrm{sec}$ once a $20^{\circ} \mathrm{C}$ increase in temperature occurred. Three duplicated wells and a negative control treatment with no template were set.

Western blot analysis. Approximately $50 \mathrm{mg}$ fresh skin specimens were homogenised with radio-immunoprecipitation assay (RIPA) lysis solution $[10 \mathrm{mmol} / 1$ Tris $\mathrm{HCl}(\mathrm{pH} 7.4)$, $150 \mathrm{mmol} / \mathrm{l} \mathrm{NaCl}, 5 \mathrm{mmol} / \mathrm{l}$ EDTA, $1 \%$ Triton-X, $50 \mathrm{mmol} / \mathrm{l}$ $\mathrm{NaF}, 0.2 \mathrm{mmol} / 1 \mathrm{Na}_{3} \mathrm{VO}_{4}, 1 \%$ sodium deoxycholate and complete mini EDTA-free protease inhibitor cocktail (Roche)]. The samples were completely homogenised for $30 \mathrm{~min}$ and allowed to crack. Following this, the samples were transferred into an EP tube and centrifuged at $8,000 \mathrm{x} \mathrm{g}$ for $20 \mathrm{~min}\left(4^{\circ} \mathrm{C}\right)$, prior to the supernatants being stored. The protein samples were electrophoresed by $15 \%$ sodium dodecyl sulphate-polyacrylamide gel electrophoresis (SDS-PAGE) and a transmembrane was formed at a constant voltage of $15 \mathrm{~V}$ for $1 \mathrm{~h}$. The membranes were blocked by $5 \%$ skimmed milk at room temperature for $1.5 \mathrm{~h}$ and then incubated with anti-CAR (Santa Cruz Biotechnology, Inc.) and anti-GAPDH (Sigma, St. Louis, MO, USA) at $4^{\circ} \mathrm{C}$ overnight, as well as with goat anti-mouse secondary antibody (Earthox, LLC, San Francisco, CA, USA) at room temperature for $2 \mathrm{~h}$. Enhanced chemiluminescence (ECL) fluorescence was determined using X-ray film in the dark. Grey-scale analysis was performed using Glyko Bandscan software (Glyko, Hayward, CA, USA).

Flow cytometry. A Vybrant apoptosis kit (Invitrogen Life Technologies) was used to detect apoptosis. The cells were incubated overnight $\left(4^{\circ} \mathrm{C}\right)$ with CAR rabbit anti-mouse antibody (Santa Cruz Biotechnology, Inc.) and then with goat anti-rabbit immunoglobulin (Ig) G-fluorescein isothiocyanate (FITC; Santa Cruz Biotechnology Inc.) secondary antibodies at room temperature for $2 \mathrm{~h}$. Following this, the samples were washed with PBS to detect apoptosis.

Statistical analysis. Experimental data were analysed using SPSS 12.0 statistical software (SPSS, Inc., Chicago, IL, USA). The CAR expression in two independent samples were 


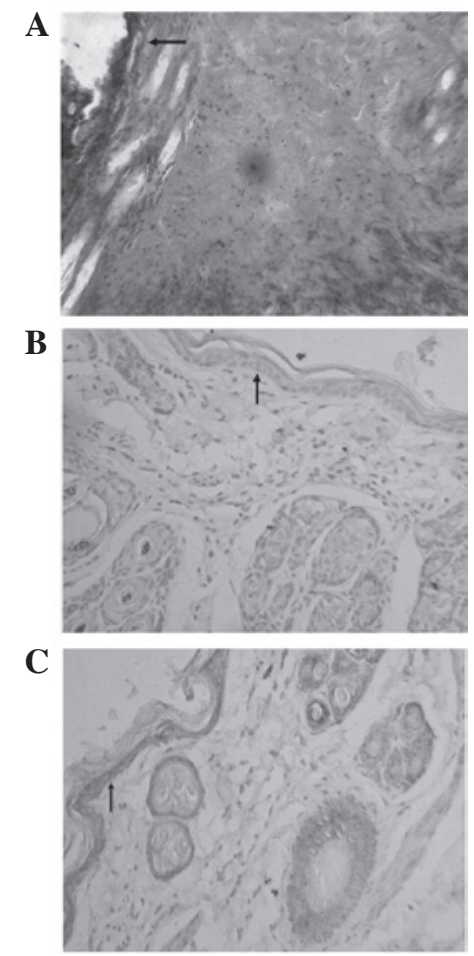

Figure 1. Histological observations. (A) Blank control; (B) epidermal keratinocytes of the normal mouse skin; (C) mouse skin epidermis following thermal stimulation. Immunostaining was used. The arrows indicate the skin epidermal keratinocytes where CAR may be expressed. Magnification, x40.

compared using one way analysis of variance (ANOVA) and the Student's t-test. $\mathrm{P}<0.05$ was considered to indicate a statistically significant difference.

\section{Results}

Histological observation. No staining was observed in the blank control specimen (Fig. 1A). In the epidermal keratinocytes of the normal mouse skin (Fig. 1B), a mild positive staining was detected, suggesting that in normal circumstances mouse skin epidermal keratinocytes express a low level of CAR. Following thermal stimulation, the positive staining of the skin epidermis (Fig. 1C) was intensified. This result indicated that thermal stimulation may lead to the upregulation of CAR expression in mouse skin keratinocytes. CAR was also expressed in hair follicles, sweat glands, and epithelial cells. By contrast, no evident expression of CAR was observed in the skin fibroblasts.

$q P C R$. In this study, the Pfaffl method (17) was used to evaluate the relative quantification of the CAR gene. The epidermal keratinocytes of the mouse skin were thermally stimulated and the results revealed that the CAR mRNA expression level of the thermally stimulated keratinocytes was significantly higher than that of the normal mouse keratinocytes $(\mathrm{P}<0.05$; Table I and Fig. 2).

Western blot. The grey-scale analysis was performed using Glyko Bandscan software and the grey-scale value of GAPDH was used as a reference. The ratio of the grey-scale value of the reference and the corresponding CAR value indicated the relative CAR expression. The results showed that there was a
Table I. Relative quantitative expression of CAR gene.

\begin{tabular}{lccc}
\hline Group & CAR Ct & GAPDH Ct & E- $\Delta \triangle \mathrm{Ct}$ \\
\hline Normal mice & $20.69 \pm 0.106$ & $15.60 \pm 0.220$ & $0.157 \pm 0.027$ \\
Scalded mice & $19.89 \pm 0.018$ & $16.98 \pm 0.048$ & $0.773 \pm 0.029^{\mathrm{a}}$ \\
\hline
\end{tabular}

$\mathrm{n}=10$ per group; ${ }^{\mathrm{a}} \mathrm{P}<0.05$ compared with normal mice. CAR, coxsackievirus and adenovirus receptor; GADPH, glyceraldehyde 3-phosphate dehydrogenase.

Table II. Relative grey value of CAR protein.

\begin{tabular}{lll}
\hline Group & $\mathrm{n}$ & $\mathrm{CAR} / \mathrm{GAPDH}$ \\
\hline Normal mice & 10 & $0.227 \pm 0.093$ \\
Scalded mice & 10 & $0.891 \pm 0.144^{\mathrm{a}}$ \\
\hline
\end{tabular}

Results are presented as the mean \pm standard deviation. ${ }^{\mathrm{a}} \mathrm{P}<0.05$ compared with normal mice. CAR, coxsackie virus and adenovirus receptor; GADPH, glyceraldehyde 3-phosphate dehydrogenase.

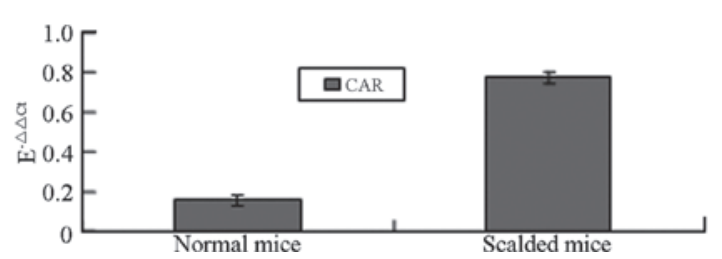

Figure 2. Effect of heat stress on the relative mRNA expression levels of the coxsackievirus and adenovirus receptor (CAR) in mouse keratinocytes.

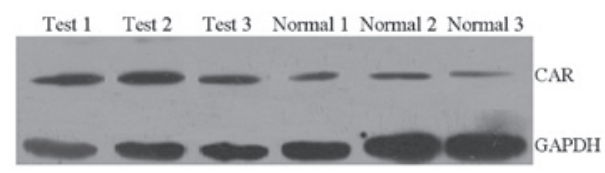

Figure 3. Relative expression of the coxsackievirus and adenovirus receptor (CAR) protein in heat-stressed (test) and normal mouse keratinocytes.

slight CAR protein expression in normal mouse skin keratinocytes and that this expression was increased in local skin keratinocytes following thermal stimulation $(\mathrm{P}<0.05$; Table II and Fig. 3).

Changes in apoptosis following heat stress. Normal keratinocytes and thermally stimulated keratinocytes were subjected to apoptosis analysis. The apoptotic rates of the normal keratinocytes and thermally stimulated keratinocytes were $5.72 \pm 1.30$ and $7.35 \pm 1.66 \%$, respectively; however, these apoptotic rates were not significantly different ( $\mathrm{P}>0.05$; Fig. 4).

CAR expression in keratinocytes following heat stress. In normally cultured keratinocytes, the expression rate of CAR was $48.36 \pm 5.07 \%$; however, this rate significantly increased to $78.64 \pm 7.96 \%$ following the cells being subjected to heat stress ( $\mathrm{P}<0.05$; Table III and Fig. 5). 
Table III. Expression of CAR in keratinocytes detected using flow cytometry (mean $\pm \mathrm{SD}) \%$.

\begin{tabular}{lcc}
\hline Group & $\mathrm{n}$ & CAR expression \\
\hline $\begin{array}{l}\text { Normal keratinocytes } \\
\text { Keratinocytes after } \\
\text { thermal stimulation }\end{array}$ & 12 & $48.36 \pm 5.07$ \\
\hline
\end{tabular}

${ }^{\text {aP }}<0.05$ compared with normal keratinocytes. CAR, coxsackie-adenovirus receptor; $\mathrm{SD}$, standard deviation.

\section{Discussion}

Wound healing occurs via different mechanisms. In contrast to skin wound biopsies, burn wounds do not undergo partial blood vessel rupture with bleeding and platelet aggregation at the vascular stump or the release of biologically active platelet-associated substances. Unlike burn wounds, skin wound biopsies exhibit few residual necrotic tissues, which may aggravate local inflammation. However, these wounds are acute; thus, their healing processes are similar (18). For keratinised epithelial cells, the increase in CAR expression in mouse skin wound biopsies was consistent with the upregulation in burn wounds. The experimental results confirmed this hypothesis, as the immunohistochemistry and western blot analyses of the skin tissues showed a significantly increased expression of CAR protein following thermal stimulation. qPCR further demonstrated that the expression of CAR mRNA in skin keratinocyte epithelial cells increased following heat stimulation, which suggests that the increase in the level of CAR expression may resulted from an enhancement of CAR gene transcription.

In vitro cell experiments were performed to determine whether the changes in CAR expression in keratinocytes following heat stress required signal exchanges with other cells. The primary keratinocytes underwent a strong thermal stimulation without the apoptotic rate being significantly affected; however, the CAR expression was significantly elevated. This result suggested that the changes in CAR expression following heat stress may be attributed to the self-stress response of cells, and that the thermally stimulated cells did not require signals from other cells to alter CAR expression.

The increased CAR expression level in the burn wounds of mice has a crucial function in wound healing. This result indicated that dendritic epidermal T cells ( $\gamma \delta \mathrm{T}$ cells, DETCs) are important in mouse skin wound healing (19); such cells may adjust to multiple factors of the process (20-23), particularly at the initiation of skin wound healing (23-27). However, mice with DETC dysfunction have an impaired wound healing response. A previous study (28) revealed that CAR in keratinocytes is able to combine with the junctional adhesion molecule-like protein (JAML) on the surface of DETCs and thereby enhance the activation level of the DETCs. This occurs via a co-stimulatory signal that passes via the phosphatidylinositol 3-kinase (PI3K)/Akt signalling pathway, thereby promoting the synthesis and secretion of interleukin (IL)-2, tumour necrosis factor (TNF) $\alpha$, keratinocyte growth factor
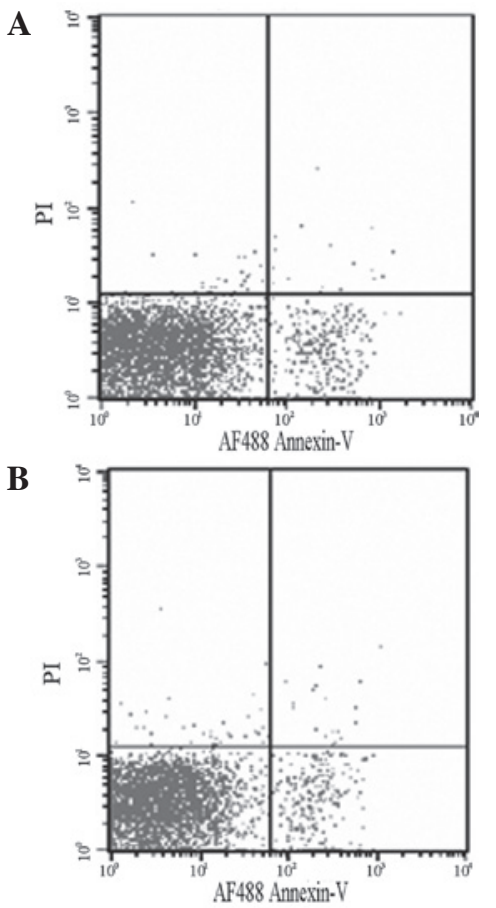

Figure 4. Detection of: (A) normal keratinocyte apoptosis; (B) keratinocyte apoptosis under heat stress.

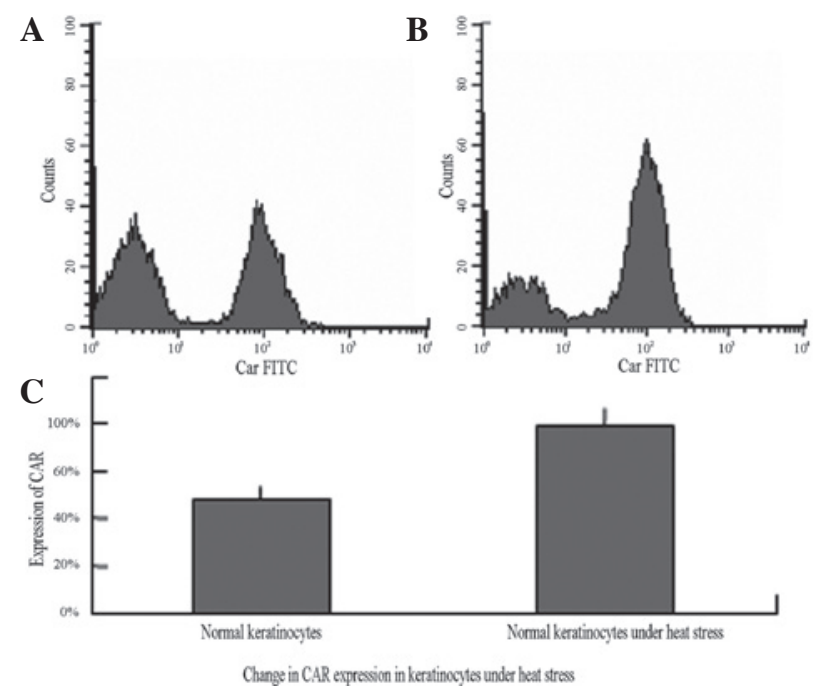

Figure 5. Expression of coxsackie-adenovirus receptor (CAR) in: (A) normal keratinocytes and (B) normal keratinocytes under heat stress. (C) CAR expression changes in keratinocytes under heat stress. FITC, fluorescein isothiocyanate.

(KGF)-1 and interferon (IFN) $\gamma$, as well as DETC proliferation for wound healing.

At present, the effect of increased CAR expression in keratinocytes remains unclear. The increased CAR expression in different cells may be a result of different self-feedback systems. Okegawa et al (29) revealed that CAR was a potential growth inhibitory factor, and that increased CAR expression in bladder cancer cells induced the upregulation of $\mathrm{p} 21$. Subsequently, retinoblastoma ( $\mathrm{Rb})$ phosphorylation and accumulation led to cell cycle arrest at the G1 phase and/or apoptosis. Bagheri et al (30) also suggested that CAR was a growth inhibitory factor, due 
to the fact that bladder carcinoma cells with high CAR expression levels demonstrated a potent binding ability to oncolytic viruses, thus showing a good oncolytic therapeutic effect. Vindrieux et al (31) also described CAR as a potential type of unknown cytokine. In breast cancer patients, CAR expression is upregulated due to the effect of oestrogen, and this phenomenon is associated with cancer cell proliferation. Since the increased CAR expression in burn wound keratinocytes is a response to injury factors, self-feedback may be inhibitory. However, this requires further investigation.

Based on the positive effect of CAR on wound healing, Verdino et al (32) studied a monoclonal antibody HL4E10a, with a molecular structure similar to that of CAR, which was able to combine with JAMLs on DETCs. Although their binding sites were not identical, this antibody was able to effectively improve the level of activated DETCs. In the same study (32), the skin wounds of mice were treated with HL4E10 and a positive effect on wound healing was observed.

CAR is widely distributed in human tissues, and an $80 \%$ homology between human and mouse CAR nucleotide sequences has been identified (33). Similar to DETCs in mice, $\gamma \delta \mathrm{T}$ cells are localised in the human skin $(34,35)$. Therefore, there is a requirement for studies to be conducted to determine whether CAR and $\gamma \delta T$ cells in humans have the same functions as CAR and DETCs in mice. A better understanding of the function of CAR in wound healing may provide a new strategy for the treatment of wound problems.

\section{References}

1. Birkballe S, Karlsmark T, Noerregaard S and Gottrup F: A new concept of a multidisciplinary lymphoedema centre: established in connection to a department of dermatology and the Copenhagen Wound Healing Center. Br J Dermatol 167: 116-122, 2012.

2. Hobizal KB and Wukich DK: Diabetic foot infections: current concept review. Diabet Foot Ankle 3, 2012.

3. Witherden DA, Verdino P, Rieder SE, et al: The junctional adhesion molecule JAML is a costimulatory receptor for epithelial $\gamma \delta$ T cell activation. Science 329: 1205-1210, 2010.

4. Philipson L and Pettersson RF: The coxsackie-adenovirus receptor - a new receptor in the immunoglobulin family involved in cell adhesion. Curr Top Microbiol Immunol 273: 87-111, 2004.

5. Gye MC, Oh YS, Lee JE, Shim S, Choi KJ and Ahn HS Expression of coxsackievirus and adenovirus receptor isoforms in developing mouse bladder uroepithelium. Urology 77: 1009. e9-1009.e18, 2011.

6. Pazirandeh A, Sultana T, Mirza M, et al: Multiple phenotypes in adult mice following inactivation of the Coxsackievirus and Adenovirus Receptor (Car) gene. Plos One 6: e20203, 2011

7. Mirza M, Pang MF, Zaini MA, et al: Essential role of the coxsackie- and adenovirus receptor (CAR) in development of the lymphatic system in mice. Plos One 7: e37523, 2012.

8. Cifuente JO, Ferrer MF, de Giusti CJ, et al: Molecular determinants of disease in coxsackievirus B1 murine infection. J Med Virol 83: 1571-1581, 2011.

9. Burckhardt CJ, Suomalainen M, Schoenenberger P, Boucke K, Hemmi S and Greber UF: Drifting motions of the adenovirus receptor CAR and immobile integrins initiate virus uncoating and membrane lytic protein exposure. Cell Host Microbe 10: 105-117, 2011.

10. Adamson RE, Frazier AA, Evans H, et al: In vitro primary cell culture as a physiologically relevant method for preclinical testing of human oncolytic adenovirus. Hum Gene Ther 23: 218-230, 2012.

11. Carson SD, Chapman NM, Hafenstein S and Tracy S: Variations of coxsackievirus B3 capsid primary structure, ligands, and stability are selected for in a coxsackievirus and adenovirus receptor-limited environment. J Virol 85: 3306-3314, 2011.
12. Martin TA, Mason MD and Jiang WG: Tight junctions in cancer metastasis. Front Biosci 16: 898-936, 2011.

13. Majhen D, Stojanović N, Špeljko T, et al: Increased expression of the coxsackie and adenovirus receptor downregulates $\alpha v \beta 3$ and $\alpha v \beta 5$ integrin expression and reduces cell adhesion and migration. Life Sci 89: 241-249, 2011.

14. Zhang X, Fang B, Mohan R and Chang JY: Coxsackie-adenovirus receptor as a novel marker of stem cells in treatment-resistant non-small cell lung cancer. Radiother Oncol 105: 250-257, 2012.

15. Wunder T, Schmid K, Wicklein D, et al: Expression of the coxsackie adenovirus receptor in neuroendocrine lung cancers and its implications for oncolytic adenoviral infection. Cancer Gene Ther 20: 25-32, 2013.

16. Shan L, Cui S, Du C, et al: A paclitaxel-conjugated adenovirus vector for targeted drug delivery for tumor therapy. Biomaterials 33: 146-162, 2012.

17. Pfaffl MW: A new mathematical model for relative quantification in real-time RT-PCR. Nucleic Acids Res 29: e45, 2001.

18. Werner S: A novel enhancer of the wound healing process: the fibroblast growth factor-binding protein. Am J Pathol 179: 2144-2147, 2011.

19. Jameson J, Ugarte K, Chen N, et al: A role for skin $\gamma \delta \mathrm{T}$ cells in wound repair. Science 296: 747-749, 2002.

20. Toulon A, Breton L, Taylor KR, et al: A role for human skin-resident T cells in wound healing. J Exp Med 206: 743-750, 2009.

21. Colburn NT, Zaal KJ, Wang F and Tuan RS: A role for $\gamma / \delta$ T cells in a mouse model of fracture healing. Arthritis Rheum 60: 1694-1703, 2009.

22. Byeseda SE, Burns AR, Dieffenbaugher S, Rumbaut RE, Smith CW and Li Z: ICAM-1 is necessary for epithelial recruitment of $\gamma \delta \mathrm{T}$ cells and efficient corneal wound healing. Am J Pathol 175: 571-579, 2009.

23. Havran WL and Jameson JM: Epidermal T cells and wound healing. J Immunol 184: 5423-5428, 2010.

24. Komori HK, Witherden DA, Kelly R, et al: Cutting edge: dendritic epidermal $\gamma \delta \mathrm{T}$ cell ligands are rapidly and locally expressed by keratinocytes following cutaneous wounding. J Immunol 188: 2972-2676, 2012.

25. Witherden DA and Havran WL: EPCR: a stress trigger for $\gamma \delta \mathrm{T}$ cells. Nat Immunol 13: 812-814, 2012.

26. Macleod AS and Havran WL: Functions of skin-resident $\gamma \delta \mathrm{T}$ cells. Cell Mol Life Sci 68: 2399-2408, 2011.

27. Chodaczek G, Papanna V, Zal MA and Zal T: Body-barrier surveillance by epidermal $\gamma \delta$ TCRs. Nat Immunol 13: 272-282, 2012.

28. Verdino P, Witherden DA, Havran WL and Wilson IA: The molecular interaction of CAR and JAML recruits the central cell signal transducer PI3K. Science 329: 1210-1214, 2010.

29. Okegawa T, Pong RC, Li Y, Bergelson JM, Sagalowsky AI and Hsieh JT: The mechanism of the growth-inhibitory effect of coxsackie and adenovirus receptor (CAR) on human bladder cancer: a functional analysis of car protein structure. Cancer Res 61: 6592-6600, 2001

30. Bagheri N, Shiina M, Lauffenburger DA and Korn WM: A dynamical systems model for combinatorial cancer therapy enhances oncolytic adenovirus efficacy by MEK-inhibition. PLoS Comput Biol 7: e1001085, 2011.

31. Vindrieux D, Le CL, Hsieh JT, et al: Coxsackie and adenovirus receptor is a target and a mediator of estrogen action in breast cancer. Endocr Relat Cancer 18: 311-321, 2011.

32. Verdino P, Witherden DA, Ferguson MS, et al: Molecular insights into $\gamma \delta \mathrm{T}$ cell costimulation by an anti-JAML antibody. Structure 19: 80-89, 2011.

33. Tomko RP, Xu R and Philipson L: HCAR and MCAR: the human and mouse cellular receptors for subgroup $C$ adenoviruses and group B coxsackieviruses. Proc Natl Acad Sci USA 94: 3352-3356, 1997.

34. Nestle FO, Di MP, Qin JZ and Nickoloff BJ: Skin immune sentinels in health and disease. Nat Rev Immunol 9: 679-691, 2009.

35. Toulon A, Breton L, Taylor KR, et al: A role for human skin-resident T cells in wound healing. J Exp Med 206: 743-750, 2009. 